\title{
Una imagen vale más que mil palabras: efectos de las advertencias sanitarias visuales en el descenso del consumo de tabaco: un estudio desde la perspectiva del marketing social ${ }^{1}$
}

\author{
An image is worth a thousand words: the effects of \\ visual health warnings in the decrease of tobacco \\ consumption: a research from the perspective of \\ social marketing
}

\author{
Juan Miguel Rey PinO ${ }^{2}$ \\ Blanca Lacave García ${ }^{3}$ \\ María IsABel Viedma del Jesús ${ }^{4}$ \\ Karine Gallopel-Morvan ${ }^{5}$
}

Recibido el 14 de diciembre de 2009, aceptado el 5 de marzo de 2010

$\mathrm{N}^{\circ}$ de clasificación JEL: M38

DOI: $10.5295 / \mathrm{cdg} .100195 \mathrm{jr}$

Reseña bibliográfica: REY, J. M.; LACAVE, B.; VIEDMA, M. I. y GALLOPEL-MORVAN, K. (2010): "Una imagen vale más que mil palabras: efectos de las advertencias sanitarias visuales en el descenso del consumo de tabaco: un estudio desde la perspectiva del marketing social", Cuadernos de Gestión, Vol 10, nº especial, pp. 149-165, DOI: 10.5295/cdg.100195jr

\section{Resumen:}

El tabaco está reconocido hoy día como un factor de riesgo muy importante en multitud de enfermedades, representando un grave riesgo para la salud pública. Entre las medidas previstas por la Organización Mundial de la Salud y por la Comisión Europea está la utilización de advertencias sanitarias sobre los efectos del tabaco

\footnotetext{
${ }^{1}$ Esta investigación pertenece al proyecto "Efectos del envase genérico y las advertencias sanitarias visuales en el descenso del consumo de tabaco: un estudio desde la perspectiva del marketing social", financiado por la Consejería de Salud de la Junta de Andalucía, Fundación Progreso y Salud.

Los autores desean agradecer a la Consejería de Salud de la Junta de Andalucia y al Institute National du Cancer Français por su apoyo y financiación.

Los autores desean agradecer las sugerencias y comentarios realizados por los revisores para mejorar este trabajo.

${ }^{2}$ Facultad de Ciencias Económicas y Empresariales, Campus de Cartuja s/n. 18071. Granada. jrey@ugr.es.

${ }^{3}$ Facultad de Ciencias Económicas y Empresariales, Glorieta de Carlos Cano s/n 11008. Cádiz. blanca.lacave@ uca.es

${ }^{4}$ Facultad de Ciencias Económicas y Empresariales, Campus de Cartuja s/n. 18071. Granada. iviedma@ugr.es

${ }^{5}$ Institute de Gestion de Rennes, 11 rue Jean Macé. 35708 Rennes Cedex 7. karine.gallopel@univ-rennes1.fr
} 
Una imagen vale más que mil palabras: efectos de las advertencias sanitarias visuales en el descenso...

en las personas. En España actualmente esas advertencias contienen solo texto. El presente trabajo centra su atención en conocer la eficacia de esas advertencias sanitarias actuales y conocer la eficacia potencial que podrían tener un banco de imágenes y texto creadas por la Unión Europea. Este trabajo forma parte de una red de proyectos que se están desarrollando también en Reino Unido y Francia y presenta los resultados realizados con metodología cualitativa-entrevistas en profundidad-.

\begin{abstract}
:
Tobacco is considered a high-risk product, associated with multiple illnesses and representing an indisputable threat for Public Health. Amongst the measures proposed by the World Health Organisation and the European Commission for controlling its use, is the employment of health warnings about the dangers of tobacco consumption. In Spain, these warnings only contain text messages. The present study focuses on assessing the efficacy of current text warnings, and on studying the potential impact of a library of images created by the European Commission on consumer behavior. This research takes place within a network of projects currently developed in France and the United Kingdom and presents results obtained in Spain by using qualitative methodology-in depth interviews-.
\end{abstract}

\title{
Palabras clave:
}

Tabaco, esquelas sanitarias combinadas, Marketing Social, investigación cualitativa.

\section{Keywords:}

Tobacco, visual health warnings, Social Marketing, qualitative research. 


\section{INTRODUCCIÓN}

Según el Plan Integral de Tabaquismo de Andalucía 2005-2010, el consumo de tabaco acelera, directa e indirectamente, procesos degenerativos que aumentan el riesgo de muerte prematura (Sistema Sanitario Público de Andalucía, 2005). Se calcula que es responsable de 5,4 millones de fallecimientos en el mundo cada año, habiendo provocado en total un número aproximado de 100 millones de muertes a lo largo del siglo XX (World Health Organisation, 2008). En la Unión Europea, son 650.000 los europeos que mueren de forma prematura por causa del tabaco (Comunidades Europeas. Dirección General de Salud y Consumidores, 2009). El Atlas del Tabaco 2009 indica que éste es responsable en nuestro país de la muerte de más del $25 \%$ de los varones adultos y de entre el 5 y el 9,9\% de las mujeres adultas (Shafey et al., 2009).

Dada la gravedad que alcanza este problema de salud pública en un gran número de países, las Administraciones Públicas se plantean dos retos ineludibles: bajar la tasa de consumo entre la población fumadora y prevenir que los individuos comiencen a fumar. Esta preocupación impulsó la elaboración de un Convenio Marco de la Lucha Antitabáquica de la Organización Mundial de la Salud (OMS) que fue firmado por 169 Estados y ratificado posteriormente por 140 países, con la intención de poner en marcha medidas eficaces para protegerse mejor de los efectos del tabaco y de las acciones promocionales de las compañías tabaqueras. Este Convenio Marco entró en vigor el 27 de febrero de 2005. Entre los 38 artículos propuestos para la lucha contra el tabaquismo, los artículos 6 a 14 presentan disposiciones relativas a las medidas para disminuir la demanda de los productos del tabaco.

Dichas actuaciones han ido precedidas de polémicas, dado que han supuesto restricciones muy importantes para las compañías tabaqueras en el uso de instrumentos de marketing, especialmente en lo referido a los instrumentos de comunicación. Efectivamente, toda publicidad o acción promocional del tabaco está completamente prohibida en la Unión Europea. Además, todos los países que se han adherido a la Convención Marco han puesto en marcha medidas de prevención basadas en mensajes de texto que van insertados en los envases de los productos del tabaco. Actualmente, una nueva generación de advertencias combinadas (texto más imagen) se están empezando a utilizar añadiendo a los textos ya existentes imágenes impactantes de los efectos que conlleva fumar sobre la salud de las personas.

Desde el 5 de septiembre de 2003, la Comisión Europea ha puesto igualmente a disposición de los países de la Unión Europea que lo deseen un banco de imágenes de 42 mensajes antitabaco. Esta decisión de la Comunidad Europea ha sido tomada como respuesta a un informe de 2002 resumiendo el impacto de los anuncios sanitarios textuales o visuales sobre los fumadores interrogados en 7 países europeos (Reino Unido, Finlandia, Francia, Alemania, Grecia, España y Suecia) (European Health Research Partnership and Centre for Tobacco Control Research, 2002). Este estudio pone de relieve que los mensajes en forma de fotografía son los más eficaces para llamar la atención, modificar la actitud de los fumadores e incitarles a dejar de fumar. Los temas propuestos por la Comisión Europea para estos anuncios son variados. Se pueden encontrar pictogramas relativos a la muerte, al tabaquismo pasivo, a la sexualidad, a la enfermedad, a la composición química del tabaco, 
a la dependencia, a dejar de fumar, a las ayudas para dejar de fumar, así como a la belleza y a los efectos sobre el feto.

Este estudio centra su atención, por un lado, en conocer la eficacia de las advertencias sanitarias que se insertan por imperativo legal actualmente en los envases de productos del tabaco (sólo texto). Asimismo, pretendemos conocer el efecto que pueden tener en la población las nuevas advertencias propuestas por la Comisión Europea ${ }^{6}$ (texto más imagen; ver en anexo). El artículo 11 del Convenio Marco de la Lucha Antitabáquica de la Organización Mundial de la Salud (OMS) se refiere al acondicionamiento y al etiquetado de los envases del tabaco. Los países son invitados a adjuntar en los paquetes de tabaco advertencias sanitarias describiendo los efectos nocivos de su consumo. Estos anuncios sanitarios deben tener un tamaño suficiente (50\% o más de la cara principal del paquete), ser visibles, claros y variados.

\section{REVISIÓN DE LA LITERATURA}

Los trabajos existentes sobre el efecto de las advertencias sanitarias insertadas en los paquetes de tabaco cuestionan el impacto que la exposición de tales mensajes tienen sobre las reacciones cognitivas, afectivas y conativo-conductuales de los individuos.

Un gran número de estudios, entre los que podemos citar Linthwaite (1985), Beltramini (1988), Cullingford et al. (1988), Magat et al. (1988), Fischer et al. (1989), Richards et al. (1989), Brubaker y Mitby (1990), Mackinnon et al. (1993), Malouff et al. (1993), Marin, (1994), Robinson y Killen (1997), Schoenbaum, (1997), Weinstein, (1998), Ayanian y Cleary (1999), Greenfield et al. (1999) y Ashley et al., (2000) ponen en evidencia la insuficiencia de las advertencias sanitarias actuales (sólo texto) en términos de impacto sobre las reacciones cognitivas (creencias, memorización, implicación, riesgo percibido o procesos de atención) y conductuales de los consumidores de productos peligrosos para la salud (tabaco, alcohol, productos peligrosos). Según los investigadores, habría un elevado número de elementos que explicarían dichos resultados. Para empezar, ciertas formas de advertencias sanitarias no favorecen demasiado su visibilidad (mensajes demasiado pequeños, poco visibles sobre el envase). Además, los anuncios no comunican bien los riesgos del producto (problema de comprensión), y parecen poco creíbles a los ojos del target. Se puede también hablar de una sobre-exposición de los individuos a las advertencias sanitarias, algo que provocaría lasitud y bajada de atención sobre los mensajes. Finalmente, el fenómeno de disonancia cognitiva, puesto en evidencia por Festinger (1957), aparece en los resultados de algunos trabajos. Esto se traduce en una pérdida de eficacia del mensaje debido a una baja estimación de los riesgos reales que corre el fumador, e incluso en un consumo mayor del producto peligroso. Este efecto perverso, llamado "boomerang", se constata cuando el fumador se expone a un mensaje excesivamente amenazante o chocante.

Debido a los pobres resultados obtenidos, resumidos anteriormente, un gran número de investigadores, entre los que citamos a Myers et al. (1981), Daube (1982), Purdy y

\footnotetext{
${ }^{6}$ Estas imágenes se encuentran disponibles en la página web http://ec.europa.eu/health/ph_determinants/life_style/ Tobacco/Documents/es_pictures.pdf
} 
Luepnitz (1982), Riley et al. (1982), Bhalla y Lastovicka (1984), Linthwaite (1985), Wogalter et al. (1987), Magat et al. (1988), Popper y Murray (1989), Wogalter et al. (1989), Cragg (1990), Jaynes y Boles (1990), Young y Wogalter (1990), Beede, Lawson y Shepherd (1991), Young (1991), Laughery et al. (1993), Barlow y Wogalter (1993), Fischer et al. (1993), Naett y Howie (1993), Borland (1997), Liefeld (1999), Mahood (1999), Nilsson (1999), Duffy y Burton (2000), Hammond et al. (2003), Hammond (2004), Hoeck et al. (2005) y Hammond et al. (2006), han cuestionado los esfuerzos necesarios para conseguir que las advertencias sanitarias sean más eficaces. Para ello, han experimentado con distintos elementos, como el tamaño (incremento de las palabras y formato de los anuncios), la forma (formas originales y presencia de iconos), el contraste de colores, la longitud del texto (más corto, más directo y simple), el contenido y el tono (uso de visuales chocantes).

La mayor parte de los trabajos aquí citados converge hacia la misma idea: parece necesario crear una ruptura con las estrategias anteriores para mejorar el impacto de esta forma de comunicación. Ello se traduce en una modificación de la forma de la advertencia sanitaria fijada sobre los paquetes de tabaco (más largo, uso de colores que contrasten) y de su contenido (corto, simple y variado). Estas tácticas se revelan pertinentes para influir en un sentido favorable sobre las reacciones cognitivas (atención, memorización, creencias con respecto a los riesgos) y actitudinales (mejor recepción de los mensajes debido a una menor lasitud) de los consumidores. Además, los mensajes visuales que suscitan emociones negativas parecen más eficaces que los mensajes neutros para motivar a los individuos e incitarles a modificar su conducta de riesgo.

Además de estas estrategias de ruptura, parece igualmente esencial segmentar las advertencias sanitarias visuales para mejorar el impacto (Daube, 1982; Beede, Lawson y Shepherd, 1991). Entre los criterios de segmentación juzgados como pertinentes en un contexto de tabaquismo se encuentran la edad, la motivación para dejar de fumar y el sexo del fumador. En lo que concierne a la edad, Linthwaite (1985), Zollar (1993) y Duffy y Burton (2000) han mostrado que el mensaje "fumar mata" interpela a los adultos, mientras que resulta poco pertinente para alcanzar al segmento de los adolescentes que se sienten lejos de un riesgo presente. De la misma manera, los mensajes visuales motivan más y son mejor comprendidos por el segmento de jóvenes fumadores con respecto a los de más edad (Malouff et al., 1993; Robinson y Killen, 1997; Duffy y Burton, 2000). La motivación para dejar de fumar es asimismo una variable fundamental para orientar el contenido de los anuncios sobre salud. En el marco del trabajo trans-teórico presentado por los autores Prochaska y DiClemente (1983) se identifican diferentes fases de motivación de los fumadores para dejar de fumar: algunos se encuentran en una denominada fase de "pre-contemplación" (no tienen intención de dejar de fumar en los seis próximos meses) mientras que otros estarían en una situación psicológica de "contemplación" (tienen la intención de dejar de fumar en los seis próximos meses). Werch y DiClemente (1994) y posteriormente Andreasen (1995) preconizan un apoyo a este modelo de diferencias psicológicas para adaptar la forma y el contenido de las comunicaciones sociales. 


\section{CUESTIONES DE INVESTIGACIÓN Y METODOLOGÍA}

La naturaleza de este estudio -exploratorio y en profundidad- hace de la metodología cualitativa la opción más adecuada para obtener un conocimiento más profundo sobre las opiniones, percepciones y actitudes de los individuos sobre las medidas propuestas por la Unión Europea para bajar la prevalencia de tabaquismo sobre la población. Como método de recogida de información se emplearon entrevistas en profundidad. Como método de análisis se utilizó la creación de unidades de significado categorizadas semánticamente según frecuencia de aparición temática.

\subsection{Cuestiones de investigación}

El objetivo básico de esta investigación es generar evidencia empírica respecto al efecto de las advertencias sanitarias sobre el comportamiento de compra de los consumidores. Dicha evidencia podrá ser utilizada para la toma de decisiones en materia de políticas de salud pública.

Los objetivos específicos de esta investigación se concretan en:

1. Respecto a las advertencias sanitarias, en primer lugar, resulta fundamental conocer el efecto de las advertencias sanitarias actuales (sólo texto) sobre el comportamiento de consumo de los españoles. Resulta imprescindible saber si estas estrategias tienen algún tipo de efecto sobre el consumo.

2. En segundo lugar, es necesario averiguar el efecto de las advertencias sanitarias combinadas (texto más imagen) propuestas por la Comisión Europea, cara a una posible implementación de estas nuevas medidas. Más concretamente, en función de los temas que abordan, habría que ver la efectividad de los diferentes temas relacionados con la apelación al miedo (muerte, enfermedades, adicción, fertilidad, belleza, salud infantil). Asimismo, habría que conocer la efectividad de los temas relacionados con soluciones (consulta a un especialista, teléfono de ayuda).

3. En función de las combinaciones en el envase (espacio en anverso y reverso) habría que conocer qué combinación de temas resulta más eficiente (apelación al miedo moderada/fuerte; apelación al miedo moderada/fuerte más propuesta de solución).

4. Finalmente, sería necesario conocer la efectividad en función de las imágenes, colores y textos, considerando su tamaño.

\subsection{La muestra}

La muestra de participantes fue inicialmente de 40 individuos. Tras aplicar procedimientos de control de calidad de las entrevistas (número de preguntas que no se respondieron, así como cantidad de información obtenida por sujeto), la muestra se redujo a 31 sujetos. Para obtener los segmentos a considerar se tuvieron en cuenta 3 variables de segmentación, dos de ellas sociodemográficas (sexo y edad) y una de comportamiento (estatus de fumador/no fumador). El número de participantes y su pertenencia a los diferentes segmentos puede observarse en la tabla 1 . 
Tabla 1

Segmentos representados en la muestra

\begin{tabular}{|l|c|c|c|c|c|}
\multicolumn{1}{|c|}{ Segmentos } & Mujer & Hombre & Mujer & Hombre & \\
\hline \multicolumn{1}{|c|}{$\mathrm{n}^{\mathrm{o}}$ participantes } & Fumadora & Fumador & No fumadora & No fumador & Total por edad \\
\hline $15-24$ & 5 & 4 & 4 & 2 & 15 \\
\hline $25-34$ & 2 & 2 & 2 & 2 & 8 \\
\hline $35-45$ & 2 & 2 & 2 & 2 & 8 \\
\hline $\begin{array}{l}\text { Total x sexo / Fumador } \\
\text { / No fumador }\end{array}$ & 9 & 8 & 8 & 6 & 31 \\
\hline
\end{tabular}

La muestra de entrevistados fue más numerosa en aquellos segmentos considerados estratégicos por las empresas del tabaco, es decir, jóvenes (15-24 años) (15 entrevistados) y mujeres (17 entrevistadas). La opinión de estos segmentos resulta especialmente relevante. En cuanto a la diferenciación por estatus de fumador también se le ha dado un mayor peso a los fumadores, especialmente en segmentos de jóvenes y mujeres. El ámbito al que pertenece este trabajo es Andalucía.

\subsection{La guía de entrevistas}

La guía de entrevistas fue elaborada a partir de la revisión bibliográfica sobre cuatro grandes temas más una pregunta sobre preferencia de imagen por tema de las 42 propuestas por la Unión Europea.

- Tema 1: Actitud general hacia el tabaco.

- Tema 2: Percepciones y actitudes hacia las esquelas insertadas actualmente.

- Tema 3: Percepciones y actitudes hacia las esquelas combinadas propuestas por la Unión Europea a los países miembros.

- Tema 4: Opinión sobre cuáles deberían ser los mensajes y fuentes en las advertencias insertadas en forma de esquelas en las cajetillas.

- Pregunta sobre imágenes más efectivas del banco de 42 imágenes más texto por tema.

- Datos demográficos de los entrevistados y técnicos de la entrevista.

\subsection{Implementación de las entrevistas}

Para la realización de la entrevista se utilizaron entrevistadores previamente entrenados. La entrevista tuvo una duración de unos 30-45 minutos aproximadamente. Los sujetos eran captados al azar, teniendo en cuenta los criterios y las cuotas asignadas. Las entrevis- 
tas tuvieron lugar en zonas tranquilas, mediante grabación de la información en grabadora digital y soporte en papel para tomar notas adicionales. Para los visionados de las cajetillas se utilizó la superposición de las imágenes en una cajetilla de Fortuna, una marca habitual de consumo en España. Se utilizó la misma marca para conocer la opinión de los entrevistados sobre las esquelas actuales.

\subsection{El procedimiento de análisis}

El procedimiento de análisis se basó en el análisis de contenido y la creación de unidades de significado a partir del texto. Es un estudio exploratorio que persigue conocer las motivaciones existentes entre los consumidores sobre el consumo de tabaco, así como sus percepciones sobre las esquelas sanitarias actualmente insertadas en las cajetillas de tabaco y las propuestas por la Unión Europea.

\section{ANÁLISIS Y RESULTADOS}

Los resultados se presentan siguiendo el orden de los temas desarrollados en la guía de entrevistas, la cual puede consultarse bajo petición a los autores.

\subsection{Comportamiento actual y actitudes frente a los productos del tabaco}

Tras pedirles a los entrevistados una tarea de asociación libre con respecto a las palabras "tabaco/cigarrillos" (lo primero que les venga a la mente), los temas más recurrentes fueron entre los fumadores el acto de fumar (7), elementos relacionados con el acto de fumar (mechero, cigarro, paquete) (4) y diferentes motivaciones que iban del placer y el aburrimiento a la necesidad y la dependencia (4). Sólo en dos individuos surgió la asociación con la enfermedad (cáncer). En cambio, las asociaciones entre los no fumadores trataban más sobre emociones negativas (repugnancia, desagrado, color negro o asco) (4), falta de salud, muerte o enfermedad (6), incomodidad (2) y en tres ocasiones hicieron referencia a situaciones sociales (amigos, fiesta y boda).

Con respecto a las situaciones de consumo variaban entre situaciones sociales (fiestas, reuniones, etc.), consumo privado en casa o en lugares tranquilos, en cualquier sitio o en ocasiones concretas (tras comer o al despertar...). Llama la atención que en un solo caso un entrevistado se refiere al hecho de fumar en lugares permitidos y en otro caso el no fumar dentro de su casa.

Sobre el número medio de cigarrillos fumados diariamente, diferían entre 2 y 40, aunque la gran mayoría oscilaba entre el paquete de tabaco diario o medio paquete. Las marcas que fumaban habitualmente eran Fortuna, Nobel, Chesterfield, LM, Ducados rubio, Winston o Gold Coast. Entre los no fumadores hubo 4 exfumadores, de los cuales dos se corresponden al perfil de exfumadores sociales (sólo fumaban en fiestas). Hasta 11 fumadores habían intentado dejar de fumar indicando como motivo principal la salud (6 indicaciones), el dinero (3) y el miedo a los problemas de salud (1). De los que intentaron dejarlo, una 
gran mayoría no lo consiguió por falta de voluntad o necesidad de fumar (8), cuestiones sociales (2), nervios (1) y uno porque no quería dejarlo realmente. Seis entrevistados indicaron fechas concretas para volver a intentar dejarlo, 4 para un futuro lejano y 2 para un futuro próximo pero sin especificar.

\subsection{Percepciones y actitudes hacia las esquelas insertadas actualmente.}

Con respecto a las esquelas insertadas actualmente en las cajetillas de tabaco todos los entrevistados -fumadores y no fumadores- habían reparado en ellas. La tasa de recuerdo de los mensajes insertados variaba notablemente, recordando, en general, mayor cantidad de mensajes los fumadores al estar continuamente expuestos a ellos. Más concretamente el mensaje más recordado fue "fumar puede matar" que se confunde a veces con "fumar mata" -mensaje que en realidad debería haber ido insertado desde el principio- (entre ambos es el mensaje más recordado -23 veces-). Apareció asimismo "fumar puede causar una muerte lenta y dolorosa". Otro mensaje que fue ampliamente recordado es que "fumar perjudica gravemente su salud y la de los que están a su alrededor" (9). Otros grupos de temas fueron:

- El grupo de temas relacionados con la esterilidad, impotencia y embarazo tuvo una alta tasa de recuerdo, especialmente entre la población femenina.

- Las enfermedades relacionadas con el cáncer, enfermedades coronarias y riesgos cardíacos, problemas cerebrales y acortamiento de la vida.

- Tabaquismo pasivo, especialmente perjudicial para los menores.

En la pregunta referida a si llaman la atención estos mensajes, 15 contestaron que sí y 16 que no, integrándose los no fumadores principalmente en el primero de estos dos grupos de respuesta, y los fumadores en el segundo de ellos.

Sobre el efecto que los mensajes actuales podrían tener sobre la población, las respuestas de los fumadores van desde que "impactan al principio pero luego la gente se habitúa", "reales pero a la gente no le importa" (10 veces citados), "son verdad", o "dan información al que fuma”. Resulta especialmente interesante citar la respuesta del entrevistado 20 (Plácido, 36 años, fumador) "son igual de graves cuando me fijo en ellos, pero se aprende a convivir con ellos sin darles la importancia de lo que significa”. En cambio, los no fumadores centraron más la atención en los aspectos positivos de los mensajes "pueden ayudar a que no fumes o a dejarlo", "llaman la atención a los no fumadores, mejor que cuando no aclaraban nada", entre otros.

A la pregunta "qué sienten cuando ven los mensajes", la respuesta más habitual entre los fumadores fue "nada" (citado 9 veces). Además, las respuestas de los fumadores van desde la indiferencia "no es suficiente, estar habituado" a la culpabilidad "cargo de conciencia, soy estúpida, fumar es una mierda, debo dejarlo". Los no fumadores se centraron más en aspectos positivos como que "informan, conciencian, están bien, impresionan, la importancia de la vida, informan del peligro o eficaces en los no fumadores pero no en los fumadores".

En cuanto al nivel de impacto que tienen los mensajes actuales, la gran mayoría comunicaron que el impacto es nulo (13 veces citado), impacto inicial pero habituación rápida al mensaje (4), temor (4), ganas de dejarlo (2), de no empezar (3) o sentirse estúpida (1). 


\subsection{Percepciones y actitudes hacia las esquelas combinadas propuestas por la Unión Europea a los países miembros}

Las primeras preguntas ( 1 y 2 ) se refieren a qué piensan, qué les inspiran y qué sienten los entrevistados sobre las esquelas sanitarias combinadas. Las respuestas variaron, aunque hubo un acuerdo generalizado en que dan miedo, aprensión, son más explícitas, reales, efectivas, mejores, se ven mejor las consecuencias, inciden en lo peligroso que es el tabaco o llamativas. Algunas respuestas fueron muy emocionales, evocando disgusto, asco, agobio, nerviosismo, crueldad, horror, negatividad o pena. Es importante incidir en el hecho de que no todos los mensajes tienen efecto según los entrevistados. También algunos señalaban la falta de efecto sobre ellos. Por último, algunos se centraron en el impacto que pueden tener para los niños pequeños. Entre las distintas afirmaciones podemos citar a Casiana (28 años, no fumadora): "son muy duros, en realidad son los mismos mensajes, pero son más explícitos"; Isabel (35 años, no fumadora): "son impactantes. Me inspiran menos ganas de fumar todavía y más conciencia a lo que te puede afectar físicamente”; María (24 años, no fumadora): "me inspiran temor, miedo al tabaco y a empezar a fumar (...) Siento nerviosismo, inquietud delante de alguno de ellos”. Además, Mercedes (20 años, fumadora) afirma: "pienso que puede llegar a funcionar si la gente se lo toma en serio, y podría funcionar, pero también pienso que la gente eso ya lo sabe y que aun así fuma... es que es un vicio, como cualquier otro. Me inspiran remordimiento de conciencia".

Con respecto a la pregunta 3 -¿Los encuentra llamativos?- la gran mayoría respondió afirmativamente (21 citas), dos negativamente y el resto de forma diversa (macabros, demasiado llamativos, depende o impactantes). Cuando se les preguntó si los encontrarían llamativos si se insertaran realmente en las cajetillas, las respuestas no variaron con respecto a la pregunta anterior. Resultan interesantes las respuestas de Plácido (36 años, fumador) "me avergonzaría” o Mercedes (20 años, fumadora): “a mi personalmente no, porque ya sé lo que causa el tabaco, y aun así no lo dejo, porque a lo mejor no tengo la suficiente conciencia para intentar dejarlo, hasta que no me pase algo... será tarde digo yo, pero..."

En las respuestas a la pregunta sobre la adecuación de colores, textos y formas, encontramos que, en general, encuentran adecuado el uso de dos colores, negro y rojo. En cuanto a la interacción entre imágenes y texto, las imágenes ayudan a reforzar lo que dice el texto -aunque en algunos casos son los textos los que consiguen hacer comprender el significado de la imagen-. La mayoría coincidió en que los mensajes eran más realistas y claros que aquellos que sólo tenían texto. Algunos se mostraron indiferentes mientras que otros consideraron que dos imágenes eran excesivamente duras (imagen del cáncer de garganta e imagen sobre estética -dientes-) (figura 1). De forma mayoritaria consideraron que los mensajes se comprendían (28 afirmaciones frente a 2 que coincidían en afirmar que dependía de la imagen). Asimismo coincidieron en señalar los mensajes como creíbles ( 24 frente a 2 que afirmaban que dependía de la imagen y otros dos que señalaban que los mensajes eran "radicales" o "exagerados" (Antonio, 24 años, fumador; Mercedes, 20 años, fumadora). Los entrevistados consideraron que los mensajes se dirigían a distintos segmentos, aunque hubo casi acuerdo en que están dirigidos a fumadores (18 citas). Otros serían no fumadores, toda la sociedad, fumadores y sus acompañantes, jóvenes, enfermos por el tabaco o fumadores muy habituales. Con respecto a si los consideraron novedosos, 
una mayoría (18 citas) opinó que no, aunque los percibían como más impactantes que los anteriores, mientras que 8 opinaron que sí eran novedosos.

A la pregunta sobre si los mensajes motivaban a hablar de ellos, la respuesta mayoritaria fue sí (26 citas), aunque con matices, como por ejemplo que estos mensajes deberían ir en otros productos que también pudieran resultar dañinos (como alimentos con mucho azúcar), o que hablarían de forma negativa de los mensajes (Rocío, 24 años, fumadora). Plácido (36 años, fumador) comentaba: "sí, diría que habrá que plantearse dejar de fumar, ya que la persecución es cada vez mayor”. Cinco entrevistados en cambio respondieron de forma negativa.

La pregunta del impacto podría tener cierto interés para conocer si estos mensajes podrían influir en las fases de cambio de conducta (Prochaska y DiClemente, 1983). El rango de respuestas abarca desde pensar en dejarlo (8 citas), efecto transitorio (4 citas), miedo, decidirme a dejar de fumar, repulsión, ninguno (respuestas entre los no fumadores) y respuestas como: "no empezar, más impacto, miedo por la gente que conozco que fuma, prohibir la venta, tener cuidado de no empezar, preocupación, ninguno, alegrarme de no fumar, avisar a los fumadores o incluso de rechazo a los fumadores". Especialmente interesante resulta la declaración de Plácido (36 años, fumador): "realmente si no me acostumbro a ellos como ha pasado con los letreros, intentaré dejar de fumar el período que esté sorprendido". En general, las percepciones muestran que estos nuevos mensajes son más efectivos que los que hay actualmente insertados en las cajetillas de cigarrillos.

La batería de mensajes combinados se presenta en catorce temas, con tres imágenes por tema (42 imágenes más texto). Las cuestiones de la guía de entrevistas que van de la pregunta 13 a la 20 buscan conocer las preferencias por temas y dentro de cada tema, así como el porqué de dicha preferencia.

Las imágenes que más calaron entre fumadores son las de partes del cuerpo, especialmente referidas a las imágenes de la garganta (cáncer externo de garganta), la imagen de boca y dientes (estética) o la imagen de los pulmones (figura 1). Los motivos principales de preferencias de estas imágenes fueron el que se pueda observar los efectos directos que tiene fumar. Los problemas de estética fueron especialmente interesantes en el sector más joven.

Figura 1

Imágenes más impactantes según la muestra

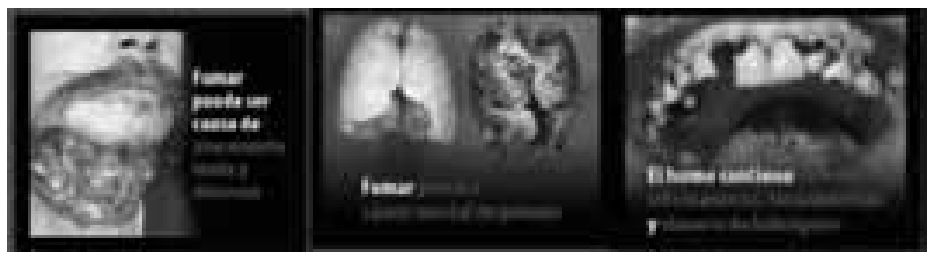

Asimismo, la aparición de niños y los efectos del tabaco sobre ellos resultaron también ampliamente comentados por los entrevistados, tanto fumadores como no fumadores, hom- 
bres y mujeres, aunque especialmente estas últimas. El motivo más argumentado es que son una porción de la población muy desprotegida y frágil.

Como motivo principal aparece el tema del cáncer (garganta, pulmones...) así como una muerte lenta y dolorosa. Entre los no fumadores, los efectos de las esquelas se centran en los seres queridos y los efectos que puede tener el tabaco sobre ellos.

Es notable que imágenes que no tienen ninguna significación directa con la cuestión (imagen de las manos, manzana, hombre corriendo en cinta o mujer paseando con un carrito vacío) resultaban peor valoradas por los entrevistados, poniendo como motivo principal precisamente la falta de esa relación. Los mensajes directos parecen tener mucho más significado. La imagen más impactante de todas fue la del cáncer de garganta, aunque en las entrevistas se mostraban dudas de que tanto esta imagen como otra valorada muy cercana a ésta -los dientes- sean imágenes reales o causadas por el tabaco. La imagen de los dientes impactaba más en el segmento joven.

Figura 2

\section{Imágenes menos impactantes según la muestra}

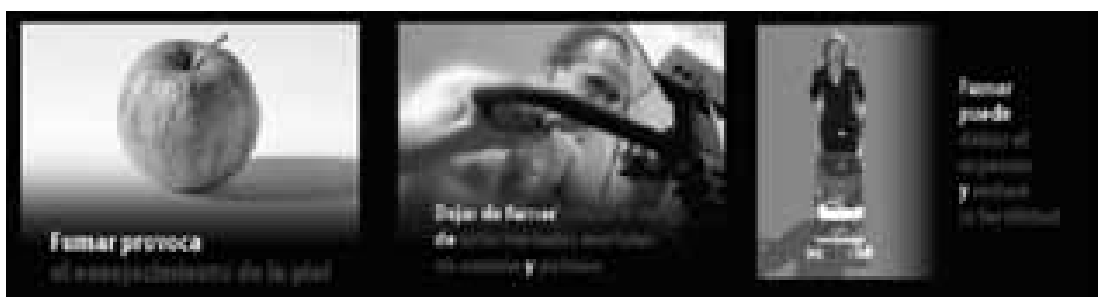

Además, resulta notorio que el tema de la ayuda no resultó muy apreciado con respecto a las imágenes que muestran los efectos de fumar, quizás porque como aparece reflejado en alguna de las entrevistas, llama más la atención las imágenes desagradables, aunque en algunos casos ese "llamar la atención” pueda ser más negativo que positivo.

\subsection{Opinión sobre cuáles deberían ser los mensajes y fuentes en las advertencias insertadas en forma de esquelas en las cajetillas}

En cuanto a estos dos temas, las respuestas fueron uniformes. En general, se estuvo de acuerdo en que los mensajes propuestos eran adecuados. En cuanto a las fuentes de los mensajes, aparecieron mayoritariamente citados las autoridades sanitarias, gobiernos, médicos, personas enfermas por culpa del tabaco o familiares de personas que hayan fallecido por culpa del tabaco. Carmen (16 años, no fumadora) afirmaba: "personas que hayan tenido algún problema por haber fumado o alguna enfermedad que sea más creíble”. José David (35 años, no fumador) hace un comentario que hace reflexionar sobre un tema controvertido: "las Autoridades Sanitarias no, porque el $46 \%$ de lo que se ingresa por tabaco va para el Estado como impuesto. Los fabricantes ninguno... ahora mismo ninguna de esas figuras me parecen creíbles, todos tienen intereses". 


\section{CONCLUSIONES}

Este trabajo representa una primera fase en el estudio de variables que desde el marketing social y el campo de prevención en salud pública pueden ayudar a disminuir la demanda de los productos del tabaco. El estudio pretende conocer las opiniones y creencias de la población sobre las medidas propuestas por la Comisión Europea a los países miembros, medidas que han sido fomentadas -entre otras- por el Convenio Marco contra el tabaquismo (F.C.T.C. en sus siglas en inglés) de la Organización Mundial de la Salud.

El estudio muestra como estas esquelas combinadas (texto e imagen) pueden ser efectivas para lograr bajar el consumo de tabaco y para evitar que consumidores comiencen a consumir, debido al miedo que las imágenes provocan y que, según la teoría de la motivación de la protección, podrían influir en la intención de no comenzar a fumar o a dejarlo (Cismaru y Lavack, 2006, 2007; Vazquez et al., 2008). De todas formas, estas medidas deberían ir acompañadas de otras, ya que una de las cuestiones que aparece a lo largo de las entrevistas es el problema de la pronta habituación que tiene el público a los mensajes, tal y como ocurre con las que van actualmente insertadas en las cajetillas (sólo de texto), ampliamente conocidas por los entrevistados pero con poco efecto según ellos mismos afirman.

Los temas propuestos parecen resultar eficaces teniendo en cuenta el efecto que provocan en los entrevistados, si bien algunos temas son mucho más notorios que otros (cáncer, muerte lenta y dolorosa y efecto del tabaco en los niños). Es preciso constatar como algunas de las imágenes no parecen ser demasiado valoradas por los entrevistados, sobre todo aquellas que no parecen guardar una relación directa con el problema (manos, manzana, hombre corriendo en la cinta), las cuales necesitan del texto imperativamente para ser comprendidas.

Es necesario plantear posibles problemas que pueden tener las esquelas combinadas en la población, especialmente en los fumadores. Son efectos de reactancia y disonancia cognitiva (Festinger, 1957). Efectivamente, las imágenes fuertes y chocantes han provocado principalmente reacciones muy adversas en algunos de los fumadores entrevistados, que parecen sentirse atacados personalmente por las imágenes. Cabe preguntarse si la realidad tan dura de las imágenes no provocará un efecto de ignorancia o rechazo del riesgo -fruto de la disonancia- en los fumadores.

El trabajo sigue una metodología cualitativa, que si bien resulta muy apta para conocer el problema en profundidad y explorarlo, hace imposible llegar a generalizaciones de los resultados así como la utilización de hipótesis de investigación. Se hace necesario realizar trabajos mediante encuestas a muestras representativas y diseños experimentales que nos permitan, a partir de la información obtenida en el estudio, llegar a conclusiones generalizables.

\section{REFERENCIAS BIBLIOGRÁFICAS}

ANDREASEN, A.R. (1995): Marketing Social Change, San Francisco, Jossey-Bass Publishers. ASHLEY, M.J.; COHEN, J.; BULL, S.; FERRENCE, R.G.; POLAND, B.; PEDERSON L.L. Y GAO, J. (2000): "Knowledge about tobacco and attitudes toward tobacco control: How different are smokers and non smokers", Canadian Journal of Public Health, n 91, pp. 376-380. 
Una imagen vale más que mil palabras: efectos de las advertencias sanitarias visuales en el descenso...

AYANIAN, J.Z. Y CLEARY, P.D. (1999): "Perceived risks of heart disease and cancer among cigarette smokers", Journal of The American Medical Association, vol. 281, no 11, pp. 1019-1021.

BARLOW, T. Y WOGALTER, M.S. (1993): "Alcohol beverage warnings in magazine and television advertisements", Journal of Consumer Research, n 20 (june), pp. 147-156.

BEEDE, P.; LAWSON, R.; SHEPHERD, M. (1991): The promotional impact of cigarette packaging: a study of adolescent responses to cigarette plain-packs, Dunedin, Nouvelle-Zélande. Department of Marketing, University of Otago.

BELTRAMINI, R.F. (1988): "Perceived believability of warning label information present in cigarette advertising", Journal of Advertising, n 17, pp. 26-32.

BHALLA, G. Y LASTOVICKA, J.L. (1984): "The impact of changing cigarette warning message content and format", Advances in Consumer Research, $\mathrm{n}^{\circ}$ 11, pp. 305-310.

BORLAND, R. (1997): "Tobacco health warnings and smoking-related cognitions and behaviours", Addiction, vol. 92, $\mathrm{n}^{\circ}$ 11, pp. 1427-1435.

BRUBAKER, R.G. Y MITBY, S.K. (1990): "Health-risk warning labels on smokeless tobacco products: Are they effective?", Addictive Behaviors, $\mathrm{n}^{\circ} 15$, pp. 115-118.

CISMARU, M. Y LAVACK, A. M. (2006): "Marketing Communications and Protection Motivation Theory: Examining Consumer Decision-Making", International Review on Public and NonProfit Marketing, vol. 3, $\mathrm{n}^{\circ}$ 2, pp. 9-24.

CISMARU, M. Y LAVACK, A. M. (2007): "Social Marketing Campaigns Aimed at Preventing and Controlling Obesity: A Review and Recommendations", International Review on Public and Non-Profit Marketing, vol. 4, $\mathrm{n}^{\circ}$ 1-2, pp. 9-30.

COMUNIDADES EUROPEAS. DIRECCIÓN GENERAL DE SALUD Y CONSUMIDORES (2009): El control del tabaco en la U.E. Folleto informativo. Bruselas. Consultado el 25/10/09 en http://ec.europa.eu/health/ph information/documents/tobacco control es.pdf

CRAGG, R. (1990): Health warnings on cigarette and tobacco packs: Report on research to inform European standardization, Health Education Authority and the Department of Health.

CULLINGFORD, R.; DA CRUZ, L.; WEBB, S.; SHEAN, R. Y JAMROZIK, K. (1988): "Legibility of health warnings on billboards that advertise cigarettes", Medical Journal of Australia, $\mathrm{n}^{\circ} 148$, pp. 336-338.

DAUBE, M. (1982): "In support of health warnings", World Smoking and Health, vol. 7, n³, pp. 42-46.

DUFFY, S.A. Y BURTON, D. (2000): "Cartoon characters as tobacco warning labels", Archives of Pediatric Adolescent Medicine, $\mathrm{n}^{\circ}$ 154, pp. 1230-1236.

EUROPEAN HEALTH RESEARCH PARTNERSHIP AND CENTRE FOR TOBACCO CONTROL RESEARCH (2002): Research into the Labeling of Tobacco products in Europe. Research report submitted to the European Commission.

FESTINGER, L. (1957): A Theory of Cognitive Dissonance, Evanston, Il., Harper Row.

FISCHER, P. M.; KRUGMAN, D. M.; FLETCHER, J. E.; FOX, R. J. Y ROJAS, T. H. (1993): “An evaluation of health warnings in cigarette advertisements using standard market research methods: What does it mean to warn?", Tobacco Control, n² 2 , pp. 279-285.

FISCHER, P.M.; RICHARDS, J.W.; BERMAN, E.F. Y KRUGMAN, D.M. (1989): "Recall and eye tracking study of adolescents viewing tobacco advertisements", The Journal of the American Medical Association, n²61, pp. 84-89.

GALLOPEL-MORVAN, K.; GABRIEL, P.; LE GALL-ELY, M.; RIEUNIER, S. Y URIEN, B. (EN PRENSA): "The use of visual warnings in social marketing: the case of tobacco", Journal of Business Research.

GREENFIELD, T.K.; GRAVES, K.L. Y KASKUTAS, L.A. (1999): "Long-term effects of alcohol warning labels: Findings from a comparison of the United States and Ontario, Canada", Psychology and Marketing, vol. 16, $\mathrm{n}^{\circ} 3$, pp. 261-282. 
HAMMOND, D.; FONG, G.T.; MCDONALD, P.W.; CAMERON, R. Y BROWN, K.S. (2003): "Impact of the graphic Canadian warning labels on adult smoking behavior", Tobacco Control, $\mathrm{n}^{\mathrm{o}}$ 12, pp. 391-395.

HAMMOND, D. (2004): Cigarette warning labels: evidence and issues in tobacco labelling policy. International Tobacco Control Evaluation Survey. University of Waterloo.

HAMMOND, D.; FONG, G.T.; MCNEILL, A.; BORLAND, R. Y CUMMINGS, K.M. (2006): "Effectiveness of cigarette warning labels in informing smokers about the risks of smoking: findings from the International Tobacco Control four country survey", Tobacco Control, $\mathrm{n}^{\circ} 15, \mathrm{pp}$. $19-25$.

HOEK, J.; MAUBACH, N.; GENDALL, P. Y SEARLE, L. (2005): Effects of on-pack warning images on young adult smokers and non smokers. Marketing and Public Policy Conference, Washington, 19-21 mayo.

JAYNES, L. Y BOLES, D.B. (1990): The effects of symbols on warning compliance, Proceedings of the Human Factors Society 34th Annual Meeting, Santa Monica, CA, Human Factors Society, pp. 984-987.

LAUGHERY, K.; YOUNG, S.; VAUGEL, K. Y BRELSFORD, J. (1993): "The noticeability of warnings on alcoholic beverages", Journal of Public Policy Marketing, $\mathrm{n}^{\circ} 12$, pp. 38-56.

LIEFELD, J.P. (1999): The relative importance of the size, content and pictures on cigarette package warning messages, Proyecto de Investigación, Department of Consumer Studies, University of Guelph.

LINTHWAITE, P. (1985): "Health warnings", Health Education Journal, vol. 44, no 4, pp. 218-219.

MACKINNON D.P.; PENTZ, M.A. Y STACY, A.W. (1993): “The alcohol warning label and adolescents: The first year", American Journal of Public Health, $\mathrm{n}^{\circ}$ 12, pp. 147-150.

MAGAT, W.; VISCUSI, W. Y HUBER, J. (1988): "Consumer processing of hazard warning information", Journal of Risk Uncertainty, $\mathrm{n}^{\circ} 1$, pp. 201-232.

MAHOOD, G. (1999): "Warnings that tell the truth: breaking new ground in Canada", Tobacco Control, $n^{\circ} 8$, pp. 356-361 (Winter).

MALOUFF, J.; SCHUTTE, N.; WIENER, K.; BRANCAZIO, C. Y FISH, D. (1993): “Important characteristics of warning displays on alcohol containers", Journal of Studies on Alcohol, $\mathrm{n}^{\circ} 54$, pp. 457-461.

MARIN, G. (1994): "Self-reported awareness of the presence of product warning messages and signs by hispanics in San Francisco", Public Health Report, $\mathrm{n}^{\circ}$ 109, pp. 275-283.

MYERS, M.L.; ISCOE, C.; JENNINGS, C.; LENOX, W.; MINSKY, E. Y SACKS, A. (1981): Staff report on the cigarette advertising investigation, Washington, D.C., Federal Trade Commission.

NAETT, C. Y HOWIE, C. (1993): The Labelling of Tobacco Products in the European Union, European Bureau for Action on Smoking Prevention.

NILSSON, T. (1999): Legibility and visual effectiveness of some proposed and current health warnings on cigarette packages, Bureau of Tobacco Control, Health Protection Branch, Environmental Health Division, Health Canada.

POPPER, E.T. Y MURRAY, K.B. (1989): “Communication effectiveness and formal effects on inad disclosure of health warnings", Journal Public Policy Marketing, n 8, pp. 109-123.

PROCHASKA, J. O. Y DICLEMENTE, C. C. (1983): "Stages and processes of self-change of smoking: toward an integrative model of change", Journal of Consulting and Clinical Psychology, $\mathrm{n}^{\circ}$ 51, pp. 390-395.

PURDY, J.E. Y LUEPNITZ, R.R. (1982): "Immediate and long-term retention for pictorial and verbal stimuli", Perceptual and Motor Skills, n 55, pp. 1079-1082.

RICHARDS, J.W.; FISCHER, P. Y CONNER, F.G. (1989): “The warnings on cigarette packages are ineffective", The Journal of the American Medical Association, vol. 261, $\mathrm{n}^{\circ}$ 1, p.45.

RILEY, M.W.; COCHRAN, D.J. Y BALLARD, J.L. (1982): "An investigation of preferred shapes for warning labels", Human Factors, n 24 (december), pp. 737-742. 
ROBINSON, T.N. Y KILLEN, J.D. (1997): "Do cigarette warnings labels reduce smoking? Paradoxical effects among adolescents", Archives of Pediatrics and Adolescent Medicine, $\mathrm{n}^{\circ} 151$, pp. 267-272.

SCHOENBAUM, M. (1997): "Do smokers understand the mortality effects of smoking? Evidence from the health and retirement survey", American Journal of Public Health, vol. 87, $\mathrm{n}^{\circ}$ 5, pp. $755-759$.

SHAFEY, O.; ERIKSEN, M.; ROSS, H. Y MACKAY, J. (2009): The Tobacco Atlas. Atlanta, Georgia, $3^{\text {a }}$ edición, American Cancer Society.

SISTEMA SANITARIO PÚBLICO DE ANDALUCÍA (2005): Plan Integral de Tabaquismo de Andalucía 2005-2010, Sevilla, Consejería de Salud, Junta de Andalucía.

WEINSTEIN, N.D. (1998): "Accuracy of smokers' risk perceptions", Annals of Behavioral Medicine, vol. $20, \mathrm{n}^{\mathrm{O}} 2$, pp. 135-140.

WERCH, C.E. Y DICLEMENTE, C.C. (1994): "A multi-component stage model for matching drug prevention strategies and messages to youth stage of use", Health Education Research, vol. 9, $\mathrm{n}^{\mathrm{o}} 1$, pp. 37-46.

WOGALTER, M.S.; GODFREY, H.J.; FONTENELLE, F.M.; DESAULNIERS, D.; ROTHSTEIN, M.A. Y LAUGHERY, K.R. (1987): "Effectiveness of warnings", Human Factors, vol. 29, no 5, pp. 599-612.

VAZQUEZ, J.L.; NAGHIU, A.; GUTIÉRREZ, P. Y GARCÍA, M. P. (2008): "Real Effectiveness of Anti-Tobacco Campaigns. An Exploratory Analysis in the Spanish Context", Buletinul Universitatii de Stiinte Agricole si Medicina Veterinara Cluj-Napoca. Seria Horticulture, vol. 65, n², pp. 396-402.

WOGALTER, M.S.; SCOTT, T.S. Y MCKENNA, N.A. (1989): "The effects of cost and social influence on warning compliance", Human Factors, n 31 (abril), pp. 133-140.

WORLD HEALTH ORGANISATION. (2008): WHO Report on the global tobacco epidemic: The MPower Package, Geneva, World Health Organisation.

YOUNG, S.L. (1991): Increasing the noticeability of warnings: Effects of pictorial, color, signal icon and border, Proceedings of the Human Factor Society 35th Annual Meeting, Santa Monica, CA, Human Factor Society, pp. 580-584.

YOUNG, S.L. Y WOGALTER, M.S. (1990): “Comprehension and memory of instruction manual warnings: Conspicuous print and pictorial icons", Human Factors, $\mathrm{n}^{\circ} 32$ (diciembre), pp. 637 649.

ZOLLAR, H. (1993): "Canada leads the way with world's toughest warnings", World Smoking and Health, vol. 18(2), pp. 5-6. 


\section{ANEXO: BANCO DE IMÁGENES PROPUESTO POR LA UNIÓN EUROPEA}

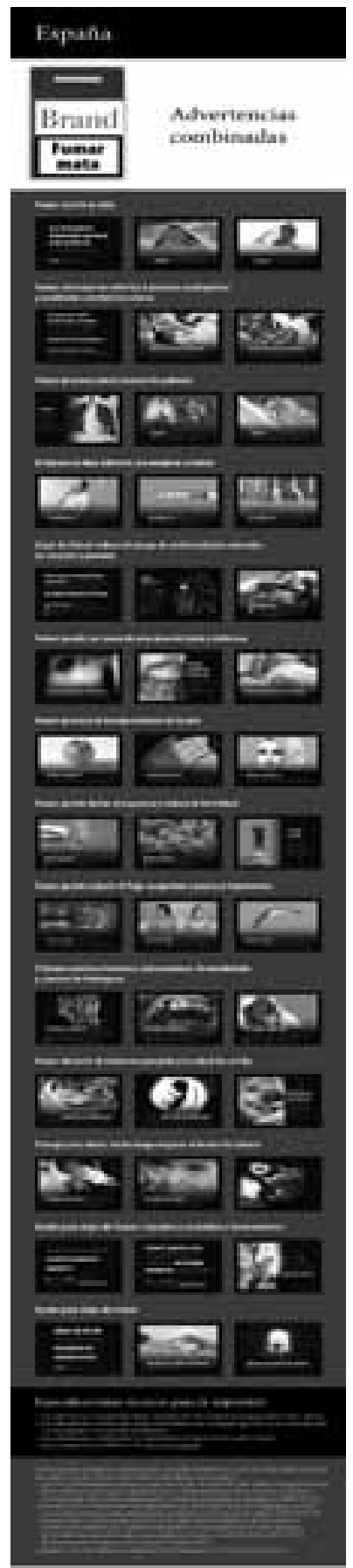


